\title{
STOMACH
}

\section{Safety and efficacy of low dose Escherichia coli enterotoxin adjuvant for urease based oral immunisation against Helicobacter pylori in healthy volunteers}

\author{
S Banerjee, A Medina-Fatimi, R Nichols, D Tendler, M Michetti, J Simon, C P Kelly, \\ T P Monath, P Michetti
}

Gut 2002;51:634-640

See end of article for authors' affiliations

Correspondence to: Dr P Michetti, Division of Gastroenteroloy and Hepatology, BH1ON-531, Centre Hospitalier Universitaire Vaudois, $\mathrm{CH}-1011$ Lausanne, Switzerland; pierre.michetti@ chuv.hospvd.ch

Accepted for publication 30 April 2002
Background and aims: Escherichia coli heat labile enterotoxin (LT) at doses of $5 \mu \mathrm{g}$ or $10 \mu \mathrm{g}$ has adjuvant activity for oral immunisation in humans infected with Helicobacter pylori, but causes severe diarrhoea. This study was undertaken to establish a safe and effective dose of $\mathrm{LT}$, to confirm the safety of recombinant urease, and to compare the immunogenicity of orally compared with enterically delivered urease.

Methods: 42 healthy adults without present or past $H$ pylori infection were randomised to receive 60 $\mathrm{mg}$ recombinant $H$ pylori urease in soluble or in encapsulated form, given with doses of LT ranging from $0 \mu \mathrm{g}$ to $2.5 \mu \mathrm{g}$. Four oral doses were administered at day 1, 8, 29, and 57. Specific $\lg G, \lg A$, and antibody secreting cells were measured as well as total $\alpha 4 \beta 7$ integrin positive lymphocyte responses. Results: Enterically delivered urease was well tolerated and no serious adverse events occurred. Mild diarrhoea (one to four loose stools) occurred after the first immunisation in 50\% (6 of 12) of the volunteers exposed to $2.5 \mathrm{\mu g} \mathrm{LT}$ ( $\mathrm{p}=0.06$; paired $t$ test, compared with baseline) but not in volunteers exposed to lower LT doses. Immune responses occurred in five ( $p=0.048$; Fisher's exact test), one, two, and one of six subjects exposed to $2.5 \mu \mathrm{g}, 0.5 \mu \mathrm{g}, 0.1 \mu \mathrm{g}$, and no LT, respectively. Significant CD4 ${ }^{+}$, $\mathrm{CD} 9^{+}$, and $\mathrm{CD} 45 \mathrm{RO}^{\mathrm{hi}}$ responses occurred over time among $\alpha 4 \beta 7^{\text {hi }}$ lymphocytes in volunteers receiving 2.5 ug LT. Enterically delivered urease induced higher lymphocyte responses than soluble urease. Conclusions: The safety of $H$ pylori urease is confirmed. Oral LT may conserve its adjuvant activity at low doses with minimal side effects.
$H$ licobacter pylori colonises the gastric mucosa of approximately half the world's population and is the major aetiological factor for chronic gastritis and peptic ulcer disease. ${ }^{1}$ Infection with $H$ pylori is also associated with the development of gastric adenocarcinoma and lymphoma. ${ }^{23}$ Eradication regimens for $H$ pylori typically yield success rates of $85 \%-90 \%$, but these rates are affected by antibiotic resistance. ${ }^{45}$ In addition, the high cost of antibiotics together with high re-infection rates in developing countries make antibiotic therapy an ineffectual approach for global control of infection, ${ }^{6}$ and alternative strategies are required to combat $H$ pylori on a large scale. Prophylactic and therapeutic vaccination, if successful in humans, would constitute an attractive and cost effective solution to this widespread health problem.

Several studies in mice and ferrets have demonstrated the feasibility of prophylactic and therapeutic vaccination against helicobacter species, achieving protection rates averaging $60 \%-80 \%{ }^{8-13}$ However, only a few clinical trials have thus far studied $H$ pylori vaccination in humans. Initial studies from our group on asymptomatic volunteers with $H$ pylori infection confirmed the safety of orally administered recombinant $H$ pylori urease, ${ }^{14}$ and indicated that urease is immunogenic when administered together with $E$ coli heat labile enterotoxin (LT) as a mucosal adjuvant. ${ }^{15}$ Administration of the vaccine with LT led to urease specific humoral and cellular immune responses and to a decrease in bacterial densities on quantitative cultures of gastric biopsy specimens. However, this vaccination regimen resulted in symptoms of severe diarrhoea (mean of 13.6 loose stools per day) in two thirds of the volunteers, prompting a decrease in the dose of administered LT from $10 \mu \mathrm{g}$ to $5 \mu \mathrm{g}$ during the course of the above study. At the lower dose of $5 \mu \mathrm{g}$ of LT, diarrhoeal symptoms improved (mean
(SD) of 4.6 (4.9) loose stools per day), but were still present. A safe and effective dose of LT therefore needs to be defined in humans.

The integrin complex $\alpha 4 \beta 7$ is a homing receptor expressed on the surface of subsets of mucosally activated lymphocytes. ${ }^{16}$ This integrin receptor interacts mainly with the vascular addressin MAdCAM-1, expressed by the gut mucosal vascular endothelium, thereby mediating preferential extravasation of $\alpha 4 \beta 7^{\text {hi }}$ lymphocytes to the lamina propria of the intestine. We have recently shown that $\alpha 4 \beta 7$ function is required for gastric mucosa homing in mice and for protection against $H$ felis infection. ${ }^{17}$ Protective oral immunisation with urease and cholera toxin in mice induced $\alpha 4 \beta 7^{\text {hi }} \mathrm{CD} 4^{+} \mathrm{T}$ cells in the gastric mucosa and protection could be abolished by the administration of anti- $\alpha 4 \beta 7$ complex antibody. The effect of oral vaccination with urease on lymphocyte $\alpha 4 \beta 7$ expression has not previously been studied in humans.

We undertook this study to establish the immunogenicity of urease in healthy subjects without past or current $H$ pylori infection. In addition, the study is designed to define the safety and adjuvant properties of low LT doses in humans and to establish whether mucosal immunisation with urease induces lymphocytes expressing $\alpha 4 \beta 7$ integrin. Secondary aims of the study were to establish the safety and immunogenicity of enterically delivered urease (administered as acid resistant capsules) as compared with orally delivered soluble urease.

Abbreviations: LT, E coli heat labile enterotoxin; UreA, $H$ pylori urease A subunit; UreB, $\mathrm{H}$ pylori urease B subunit 


\section{METHODS}

Study subjects

Study subjects were $H$ pylori negative asymptomatic healthy volunteers. The absence of infection with $H$ pylori was confirmed by a combination of negative $H$ pylori serology (FlexSure; Beckman Coulter, Fullerton, CA) and ${ }^{13} \mathrm{C}$ urea breath test (Meretek, Nashville, TN) as previously described. ${ }^{15}$ Eligible subjects had no history of gastrointestinal disease, immunodeficiency, alcohol or drug misuse, or of other chronic medical or psychiatric illness. None of the study subjects had received treatment with immunosuppressive agents, nonsteroidal anti-inflammatory drugs, or antisecretory drugs over the preceeding 12 months. All volunteers had a normal physical examination and normal screening laboratory tests including a complete blood count, chemistry, and urine analysis. Pregnant and nursing women were excluded from the study and women of childbearing age were required to practice contraception through the course of the study. A serum pregnancy test was performed before entry into the study and 48 hours preceding each vaccination. Written informed consent was obtained from all study subjects. The study protocol was approved by the Institutional Review Board at Beth Israel Deaconess Medical Center, Harvard Medical School, Boston, MA.

\section{Vaccine and adjuvant}

Recombinant, enzymatically inactive urease (rUrease) was produced from $E$ coli containing a plasmid with the ureA and ure $B$ genes of $H$ pylori downstream from a T7 promoter (OraVax, Cambridge, MA, and Walter Reed Army Institute of Research, Forest Glen, MD). The final product contains $>95 \%$ intact UreA and UreB subunits, of which over $70 \%$ is in a multimeric form of molecular weight $550 \mathrm{kDa}-600 \mathrm{kDa}$. Endotoxin levels were not part of the release criteria for the products used in this study and are not available. The rUrease was administered orally either in the liquid form, or as acid resistant enterically coated capsules (Capsugel, Morris Plains, NJ and University Pharmaceuticals, Baltimore, MD).

LT was produced from E coli strain Hc22/TP235 at the Swiss Serum and Vaccine Institute, Bern, Switzerland, under good manufacturing practices. LT was purified as described previously ${ }^{18}$ and lyophilised in phosphate buffer containing $10 \%$ lactose. Because of FDA restrictions, LT could not be combined with urease in the acid resistant capsules and was therefore administered separately.

\section{Study protocol}

The study followed a randomised, double blind, placebo controlled design. The treatment consisted of administration of rUrease orally either in the liquid from or in the acid resistant capsules together with LT as mucosal adjuvant. Patients were randomised to one of seven treatment groups and received either soluble rUrease or rUrease capsules, together: group 1, soluble urease $60 \mathrm{mg}$ with no LT; group 2, soluble urease $60 \mathrm{mg}$ with $0.1 \mu \mathrm{g} \mathrm{LT}$; group 3, soluble urease $60 \mathrm{mg}$ with $0.5 \mu \mathrm{g} \mathrm{LT}$; group 4, soluble urease $60 \mathrm{mg}$ with $2.5 \mu \mathrm{g} \mathrm{LT}$; group 5, urease capsules $60 \mathrm{mg}$ with no LT; group 6, urease capsules $60 \mathrm{mg}$ with $0.1 \mu \mathrm{g}$ LT; group 7, urease capsules with $2.5 \mu \mathrm{g} \mathrm{LT}$.

All study volunteers were vaccinated orally on four occasions, on days $1,7,28$, and 56 . Twenty five volunteers were vaccinated orally on a fifth occasion on day 64 (four volunteers each from groups $1,2,4$, and 6, and three volunteers each from groups 3, 5, and 7). The study subjects were fasted for eight hours before receiving the oral vaccine. All subjects were given $120 \mathrm{ml}$ of $1 \% \mathrm{NaHCO}_{3}$ buffer solution in an effort to neutralise gastric acid two minutes before receiving oral vaccination. The subjects then ingested $35 \mathrm{ml}$ of rUrease liquid or placebo and $10 \mathrm{ml}$ of LT solution or placebo. A further $30 \mathrm{ml}$ of $\mathrm{NaHCO}_{3}$ buffer solution was then given. The subjects were subsequently monitored for an hour for any adverse reactions. At the end of this hour, subjects were given three acid resistant capsules containing rUrease/placebo (UPM, Baltimore MD for OraVax, MA). Administration of capsules was delayed to avoid $\mathrm{pH}$ dependent dissolution in the stomach as a consequence of the administration of bicarbonate. Subjects were then permitted to have liquid nourishment consisting of beverages without citric acid or fat, but no solid food for a further three hours.

\section{Safety assessments and laboratory tests}

Participants were asked to complete a symptom diary one week before and throughout the treatment period to record any possible adverse events and the number and consistency of bowel movements. Three days after each immunisation, a targeted medical history and physical examination was carried out. Blood and urine sample were obtained at baseline, at three days after each immunisation, and at the end of the study to monitor the complete blood count with differential, the prothrombin and partial thromboplastin time, serum electrolytes, glucose, liver and renal function tests, lipase, amylase, and urine analysis.

Immune responses to vaccination were assessed by measuring serum anti-urease and anti-LT IgG and IgA antibodies at baseline and seven days after each immunisation. Stool sample was collected at baseline and five to eight days after each immunisation. Circulating antibody secreting cells were quantified in peripheral blood by ELISPOT. Expression of surface markers on total lymphocytes was evaluated by flow cytometry at baseline and seven days after each immunisation.

\section{Detection of total and specific antibody secreting cells}

Circulating specific antibody secreting cells were quantified by ELISPOT on frozen circulating cells. ${ }^{19}$ Serial cell dilutions were plated in four replicate wells in 96 well microtitre plates (Nunc, Naperville, IL) coated with rUrease or LT and incubated overnight at $37^{\circ} \mathrm{C}$. Plates were then washed with phosphate buffered saline and incubated with phosphatase labelled goat antihuman IgA (anti- $\alpha 1$ and $\alpha 2$ chains) or IgG antibodies for one hour at $37^{\circ} \mathrm{C}$ (All antibodies from Kirkegaard \& Perry Laboratories, Gaithersburg, MD). After additional washes, a $8 \mathrm{mM} \mathrm{MgCl}_{2}, 0.1 \% p$-nitroblue tetrazolium chloride, $0.01 \%$ 5-bromo-4-chloro-3-indolyl phosphate, $1.4 \%$ agarose, $80 \%$ Barbital (all from Sigma) substrate overlay solution was applied to the plates and blue spots enumerated. Secondary antibodies were tested for lack of cross reactivity between IgA and IgG antibody isotypes.

\section{Antigen specific ELISA}

Serum anti-urease and anti-LT IgG and IgA levels were determined in serial dilutions on 96 well Immulon 3 plates coated with purified urease (strain ATCC 11637) or LT as appropriate. Secondary conjugated goat antihuman IgA or mouse antihuman IgG (Southern Biotechnology) antibodies and substrate solution were used as described above. Plates were read at $405 \mathrm{~nm}$ after 40 minutes at $28^{\circ} \mathrm{C}$. Results of duplicate samples were averaged and expressed as ELISA Units by comparison to the values obtained for standard curves established with human serum containing high anti-urease activity. Serum from $H$ pylori positive and $H$ pylori negative subjects served as controls.

\section{Flow cytometry}

Expression of cell surface markers on freshly isolated circulating mononucleated cells was determined by double staining with FITC and PE conjugated antibodies. Conjugated antibodies used in this study included anti-CD4 (clone RPA-T4), antiCD19 (used as a broad B cell marker, clone HIB19), anti-CD45RO (clone UCHL1), and anti-CD69 (clone FN-50, all from Pharmingen, San Diego, CA). Purified $\alpha 4 \beta 7$ integrin antibody (clone ACT-1) was kindly provided by $\mathrm{Dr} W$ 


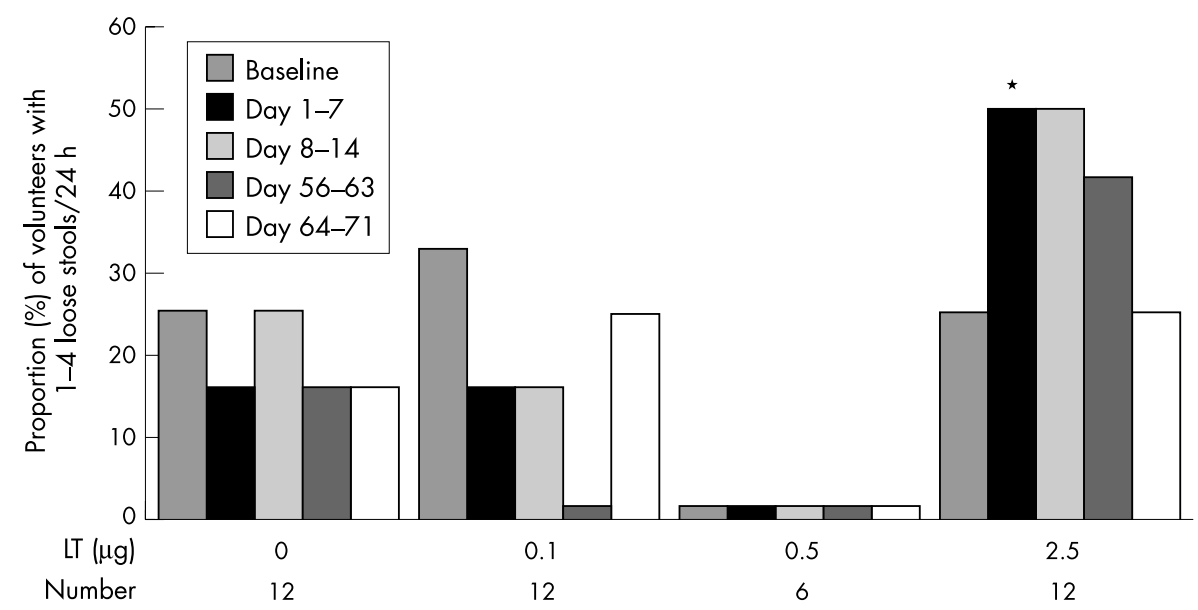

Figure 1 Proportions of volunteers developing diarrhoea (one to four loose stools/day) in the $0 \mu \mathrm{g}, 0.1 \mu \mathrm{g}, 0.5 \mu \mathrm{g}$, and $2.5 \mu \mathrm{g}$ LT groups after baseline and subsequent immunisations. Results are shown grouped by LT dose. Differences are evaluated by paired $t$ tests compared with baseline. ${ }^{*} \mathrm{p}=0.06, t$ test compared with baseline.

Newman, PhD, LeukoSite, Cambridge, MA. Cells were aliquoted at $4^{\circ} \mathrm{C}$ in Hanks's balanced salt solution (HBSS) supplemented with $1 \%$ bovine serum albumin and $0.1 \%$ sodium azide. Cells were incubated with biotinylated anti$\alpha 4 \beta 7$ integrin $\left(0.5 \mu \mathrm{g} / 10^{6}\right.$ cells $)$ for 20 minutes at $4^{\circ} \mathrm{C}$, washed and then incubated with PE-streptavidin with one of the other antibodies according to supplier's instructions. Cells were then washed twice and fixed in $1 \%$ paraformaldehyde in HBSS before analysis using a FACS analyser (Becton Dickinson, San Jose, CA). An identical broad lymphocyte gate was applied to all samples. The results of double staining are presented as percentage of total $\alpha 4 \beta 7^{\text {hi }}$ cell population coexpressing CD4, CD19, CD45RO, or CD69 markers. Because $\alpha 4 \beta 7$ integrin and CD45RO expression and staining do not result in discrete positive and negative peaks of expression on lymphocytes, the threshold for high expression was defined based on values obtained with cells stained with an irrelevant isotypematched control antibody (Pharmingen). Cells were considered as $\alpha 4 \beta 7^{\text {hi }}$ or $C D 45 R O^{\text {hi }}$ if their level of fluorescence, measured by flow cytometry, was at least 1.2 times above the maximal level measured in cells stained with the control antibody.

\section{Statistical methods}

Demographic variables and occurrence of side effects in the various groups were compared by Fisher's exact test. Wilcoxon's rank sum tests were used to compare the results of the various study groups. Within each group, changes from baseline to after immunisation were assessed using paired $t$ tests. Multiple comparisons were analysed using one way analysis of variance plus Bonferroni's correction.

\section{RESULTS}

Fifty seven healthy asymptomatic volunteers were screened for possible enrollment into this study. Of these, $42 \mathrm{H}$ pylori negative volunteers with no exclusion criteria were enrolled into the study, with six volunteers being randomised to each of the seven treatment groups. The volunteers were aged 23-50 years (mean (SD) 30.4 (6.5) years) and 20 of the 42 were male. All 42 volunteers completed the study.

\section{Safety profile of soluble and enterically delivered urease}

Both soluble urease and enterically delivered urease were found to be safe and no significant adverse events or clinically relevant abnormalities in blood count or chemistry were noted with their use.

\section{Safety profile of low dose LT}

Mild diarrhoea (ranging from one to four loose stools) occurred after the first and second immunisations in 6 of 12 volunteers (50\%) receiving $2.5 \mu \mathrm{g}$ LT as adjuvant (fig 1 ). In all cases, stools normalised within 36 hours after immunisation. This approached significance compared with baseline ( $\mathrm{p}=0.06$; paired $t$ test). None of the volunteers receiving $2.5 \mu \mathrm{g}$ LT experienced diarrhoea more severe than four loose stools a day. The proportion of volunteers developing mild diarrhoea with the lower doses of LT of 0.1 or $0.5 \mu \mathrm{g}$ did not differ from baseline or from those receiving no LT. Among patients receiving $2.5 \mu \mathrm{g}$ of LT, there was a gradual decrease in the proportion of patients experiencing diarrhoea after the third and fourth vaccination (fig 1), and the proportion of patients experiencing mild diarrhoea after the fourth vaccination did not differ

\begin{tabular}{|c|c|c|c|c|}
\hline & $\begin{array}{l}\text { Serum antiurease lgG } \\
\text { positive/total } \\
\text { volunteers* }\end{array}$ & $\begin{array}{l}\text { Serum antiurease IgG } \\
\text { titre mediant (range) }\end{array}$ & $\begin{array}{l}\text { Serum antiurease IgA } \\
\text { positive/total } \\
\text { volunteers* }\end{array}$ & $\begin{array}{l}\text { Serum antiurease IgA } \\
\text { titre mediant (range) }\end{array}$ \\
\hline Group 1: Soluble urease, no LT & $0 / 6$ & N/A & $1 / 6$ & 4.7 \\
\hline Group 2: Soluble urease, $0.1 \mu \mathrm{LTT}$ & $1 / 6$ & 15.4 & $1 / 6$ & 5.3 \\
\hline Group 3: Soluble urease, $0.5 \mu g$ LT & $1 / 6$ & 4.2 & $0 / 6$ & N/A \\
\hline Group 4: Soluble urease, $2.5 \mu \mathrm{LT} \ddagger$ & $2 / 5$ & $58(6.5-109.8)$ & $3 / 5$ & $4.5(4.1-28.3)$ \\
\hline Group 5: Urease capsule, no LT & $1 / 6$ & 152 & $1 / 6$ & 24.8 \\
\hline Group 6: Urease capsule, 0.1 pg LT & $1 / 6$ & 7.3 & $1 / 6$ & 9.9 \\
\hline Group 7: Urease capsule, $2.5 \mathrm{\mu g}$ LT & $1 / 6$ & 15.3 & $2 / 6$ & $4.3(4.2-4.4)$ \\
\hline
\end{tabular}

*Positive status defined as a fourfold increase from baseline. †Titres are expressed as fold change as compared with baseline. Positive results only. $\ddagger$ One serum sample not available for analysis. 
Table 2 Peripheral blood urease specific $\lg G$ and $\lg A$ antibody secreting cells (ASC) by treatment group

\begin{tabular}{|c|c|c|c|c|}
\hline & $\begin{array}{l}\text { Antiurease IgG secreting } \\
\text { cells positive/total } \\
\text { volunteers* }\end{array}$ & $\begin{array}{l}\text { Antiurease lgG peak } \\
\text { ASC mediant (range) } \\
\text { [day to peak] }\end{array}$ & $\begin{array}{l}\text { Antiurease IgA secreting } \\
\text { cells positive/total } \\
\text { volunteers* }\end{array}$ & $\begin{array}{l}\text { Antiurease IgA peak } \\
\text { ASC mediant (range) } \\
\text { [day to peak] }\end{array}$ \\
\hline Group 1: Soluble urease, no LT & $1 / 6$ & $80[73]$ & $1 / 6$ & $30[73]$ \\
\hline Group 2: Soluble urease, $0.1 \mu \mathrm{g} \mathrm{LT}$ & $1 / 6$ & $129[73]$ & $2 / 6$ & 35 (30-39) [69] \\
\hline Group 3: Soluble urease, $0.5 \mu \mathrm{g}$ LT & $1 / 6$ & $130[64]$ & $1 / 6$ & $146[64]$ \\
\hline Group 4: Soluble urease, $2.5 \mu \mathrm{g} \mathrm{LT}$ & $3 / 6$ & $110(40-139)[36]$ & $1 / 6$ & $150[36]$ \\
\hline Group 5: Urease capsule, no LT & $1 / 6$ & $800[64]$ & $1 / 6$ & $299[64]$ \\
\hline Group 6: Urease capsule, $0.1 \mu \mathrm{g} \mathrm{LT}$ & $1 / 6$ & $70[64]$ & $1 / 6$ & $100[64]$ \\
\hline Group 7: Urease capsule, 2.5 jg LT & $2 / 6$ & $40(40-40)[73]$ & $1 / 6$ & $16[44]$ \\
\hline
\end{tabular}

from baseline. No other significant adverse events or clinically relevant abnormalities in blood count or chemistry were observed.

\section{Humoral immune response}

Seroconversion was defined as a fourfold increase in titres of IgA or IgG (table 1), or as more than 15 urease specific IgG antibody secreting cells $/ 10^{6}$ cells (table 2 ). According to these criteria, $67 \%$ of patients $(n=12)$ responded to immunisation with either soluble urease or urease capsules and $2.5 \mu \mathrm{g}$ of LT, with lower numbers responding to lower doses of LT in both groups (fig 2). None of these results was individually significant compared with volunteers receiving no LT. When results of both the soluble urease and urease capsule groups were pooled by the LT dose, the proportions of serological responders were $67 \%(p=0.048$; Fisher's exact test $), 17 \%, 33 \%$, and $25 \%$ among subjects who received $2.5 \mu \mathrm{g}, 0.5 \mu \mathrm{g}, 0.1 \mu \mathrm{g}$, and no LT, respectively.

Only one of 12 volunteers receiving $2.5 \mu \mathrm{g}$ of LT was found to develop IgG anti LT antibodies by ELISA. No IgA LT antibodies were detected. Anti-LT seroconversion was not seen with the lower doses of LT. Two volunteers exposed to urease without LT seroconverted according to these criteria.

\section{Cellular immune response}

Significant $\mathrm{CD}^{+}, \mathrm{CD} 9^{+}$, and $\mathrm{CD} 45 \mathrm{RO}^{\text {hi }}$ responses occurred over time among $\alpha 4 \beta 7^{+}$lymphocytes in volunteers receiving $2.5 \mu \mathrm{g} \mathrm{LT}$, but not with lower doses of adjuvant (fig 3). The proportion of activated $\alpha 4 \beta 7^{\text {hi }} \mathrm{CD} 9^{+}$cells increased significantly, from $64.5 \%$ at baseline to $81.8 \%$ at day $8(p \geqslant 0.05$, paired $t$ test), $85 \%$ at 64 days ( $\mathrm{p}<0.05$, paired $t$ test), and 87.2 $\%$ at 73 days $(\mathrm{p}<0.05$, paired $t$ test $)$. This increase remained significant after correction for multiple comparisons ( $p=0.008$, one way analysis of variance). The proportion of $\alpha 4 \beta 7^{\text {hi }} \mathrm{CD}^{+}$cells and of $\alpha 4 \beta 7^{\text {hi }}$ CD $45 \mathrm{RO}^{\text {hi }}$ memory cells also increased $(\mathrm{p}<0.05$, paired $t$ test in both series) but these changes only showed strong trends when corrected for multiple comparisons $(p=0.07$, one way analysis of variance in both series). No significant increase was noted in $\alpha 4 \beta 7^{\text {hi }}$ $\mathrm{CD} 9^{+}$cells with vaccination $(94.3 \vee 95.6)$. In volunteers receiving $2.5 \mu \mathrm{g}$ LT, enterically delivered urease as acid resistant capsules seemed more effective than soluble urease (urease liquid) in inducing lymphocyte responses, although the numbers of volunteers in this subgroup were small $(n=3$ to 4 per group). Thus, subgroup analysis of the $2.5 \mu \mathrm{g}$ LT subset, indicated a significant increase in the proportion of $\alpha 4 \beta 7^{\text {hi }}$ $\mathrm{CD} 9^{+}$cells in volunteers receiving urease capsules $(\mathrm{p}=0.013$,

Seroconversion $(\%)$

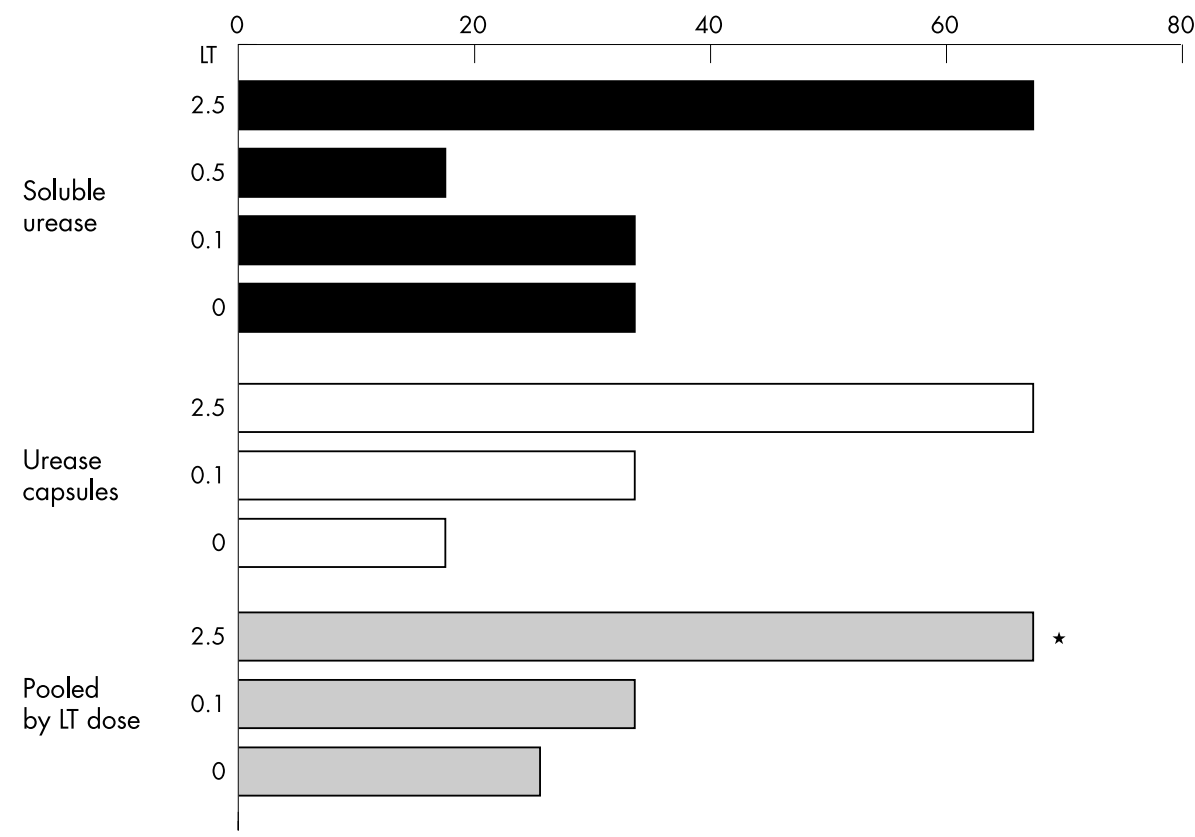

Figure 2 Proportions of seroconverters with $0 \mu \mathrm{g}, 0.1 \mu \mathrm{g}, 0.5 \mu \mathrm{g}$, and $2.5 \mu \mathrm{g}$ of $\mathrm{LT}$ in the soluble urease group, the urease capsule group, and in both urease groups combined. Each volunteer with either a fourfold increase in $\lg G$ or $\lg A$ titres, or a positive status for ASC $\lg G$ or $\lg A$ as defined in table 2 was considered as having achieved seroconversion. ( $n=12$ in the pooled series). ${ }^{*} p=0.04$, Fisher's exact test compared with no LT. 

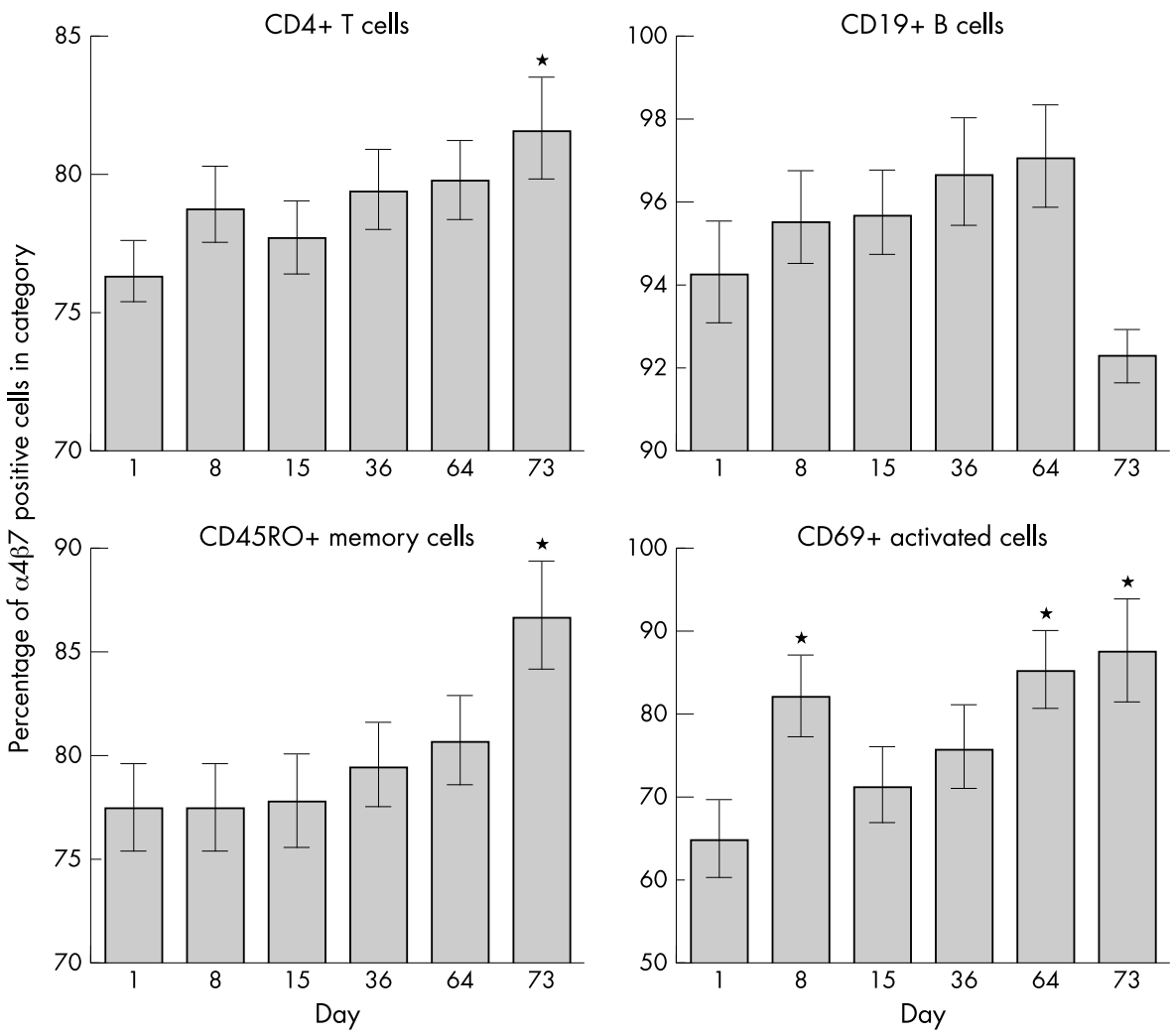

Figure 3 Lymphocyte responses to oral immunisation with $60 \mathrm{mg}$ urease and $2.5 \mu \mathrm{LT}$ ( $\mathrm{n}=12$ ). Mean (SD) percentages of $\alpha 4 \beta 7^{\text {hi }}$ lymphocytes coexpressing CD4, CD19, CD45RO, and CD69 antigens at baseline and after subsequent immunisations are presented. Differences were evaluated by paired $t$ tests compared with baseline and by one way analysis of variance with Bonferroni's correction for multiple analyses (see text for results of this analysis). ${ }^{*} p<0.05$ compared with day 1.

one way analysis of variance) The proportions of $\alpha 4 \beta 7^{\text {hi }} \mathrm{CD} 4^{+}$ and $\alpha 4 \beta 7^{\text {hi }} \mathrm{CD} 45 \mathrm{RO} \mathrm{O}^{\text {hi }}$ cells were not found increased after correction for multiple analyses in this subgroup analysis.

\section{DISCUSSION}

This study shows that oral immunisation with rUrease and LT is immunogenic in healthy human subjects not previously or currently infected by $H$ pylori. Our results also show that LT retains some mucosal adjuvant activity at a dose of $2.5 \mu \mathrm{g}$, stimulating both humoral and cell mediated immune responses, but is ineffective when administered at the lower doses of $0.5 \mu \mathrm{g}$ and $0.1 \mu \mathrm{g}$. LT has been used as an oral vaccine adjuvant in humans in only one prior study, ${ }^{15}$ where significant diarrhoea was noted after its use at the higher doses of $10 \mu \mathrm{g}$ and $5 \mu \mathrm{g}$. Defining a safe and effective dose of LT in humans represents therefore a potentially important step in the development of future oral vaccines, including $H$ pylori vaccines. At a dose of $2.5 \mu \mathrm{g}$ LT is acceptably tolerated, with only $50 \%$ of volunteers developing mild (one to four loose stools/d) diarrhoea, which was manageable and did not interfere with their daily functioning. No other significant adverse events were seen with LT. Further studies are needed to confirm these results and further define the optimal dose of LT in humans.

As with our previous study, ${ }^{15}$ we found that the proportion of patients developing diarrhoea diminished with repeated vaccination. The number of patients with mild diarrhoea after the fifth administration of LT with rUrease was similar to that at baseline, or in the no LT group. We had earlier postulated that this diminishing toxicity might be attributable to the development of a protective immune response to LT and we therefore measured levels of IgA and IgG antibodies against LT in all volunteers in this study. We were able to record IgG anti-LT seroconversion in only one study volunteer, receiving the highest LT dose of $2.5 \mu \mathrm{g}$. This does not rule out the possibility that improved tolerance to repeat LT exposure results from the development of a local immune response. The level of immunity induced by low dose LT may be too low to be detected in blood, or may be limited to a mucosal immune response. If the development of an anti-LT immune response is responsible for the improvement in diarrhoea upon repeated vaccination, this response may also interfere with LT adjuvant activity. Subsequent studies should therefore assess the benefit of escalating the dose of LT in the course of repeated vaccinations, in order to maintain adjuvant activity.

Although lower doses of LT $(0.1 \mu \mathrm{g}$ and $0.5 \mu \mathrm{g})$ did not result in significant diarrhoea, they were not immunogenic. Taken together with the results of our previous studies, these data suggest that both LT adjuvant activity and toxicity are dose related. Indeed, in our previous study, human volunteers receiving $10 \mu \mathrm{g}$ of $\mathrm{LT}$ had a non-significant trend towards developing higher ASC responses than those receiving the lower dose of $5 \mu \mathrm{g} \mathrm{LT} .^{15}$ The ranges of urease specific IgG and IgA ASC numbers observed in this study are similar to those observed during our previous study with higher doses of LT. To circumvent its toxicity by the oral route, LT could be detoxified or administered by other routes. ${ }^{2021}$

As with humoral immune responses, we found that cellular immune responses developed only with $2.5 \mu \mathrm{g}$ of LT and were not seen with lower doses of the adjuvant. This dose therefore seems to be the lowest immunogenic oral dose of LT in humans. The level of immune response observed during this study, as indicated by ELISPOT and ELISA titres, is comparable to those previously observed by us and by others after mucosal immunisation. ${ }^{152}$ The value of peripheral blood ELISPOT in the assessment of mucosal immune response has been previously defined. ${ }^{23}$ These responses are short lived, with a peak five to seven days after immunisation. This response thus usually precedes serum antibody responses, 
which require accumulation of plasma cells, and appear usually later. In our experience, IgA ASC responses were associated with decreased gastric colonisation with $H$ pylori. The level of response was comparable in magnitude to the levels observed here. Despite the differences in experimental setting, it may thus be speculated that the level of response obtained with $2.5 \mu \mathrm{g}$ of LT is sufficient to provide some degree of protection, and that low dose LT may provide adjuvant effect to trigger a protective immune response.

We used $\alpha 4 \beta 7$ integrin expression as a marker of mucosal immune response. ${ }^{25}$ Indeed, naive lymphocytes express $\mathrm{L}$ selectin and low levels of $\alpha 4 \beta 7$ integrin. After activation in Peyer's patches or other mucosal inductive sites, lymphocytes shed $L$ selectin, but increased expression of $\alpha 4 \beta 7$ integrin. This homing receptor directs activated lymphocytes and other $\alpha 4 \beta 7^{\text {hi }}$ cells back to mucosal surfaces, including the gastric and intestinal mucosa. ${ }^{16}$

We have previously shown in mice that $\alpha 4 \beta 7$ integrin function is required for protection against helicobacter infection after oral immunisation. Protective oral immunisation with urease and cholera toxin in mice induced high numbers of $\alpha 4 \beta 7^{\text {hi }} \mathrm{CD}^{+} \mathrm{T}$ cells in the gastric mucosa and protection was abolished by the administration of $\alpha 4 \beta 7$ antibody. ${ }^{17}$ The $\alpha 4 \beta 7^{\text {hi }}$ lymphocyte responses after vaccination in our study volunteers were subgrouped depending on the coexpression of the CD4 and CD19 antigens. We also estimated the proportions of $\alpha 4 \beta 7^{\text {hi }}$ lymphocytes expressing activation (CD69) or memory markers (CD45RO) antigens. No significant increase in CD19 ${ }^{+}$ lymphocytes was seen after immunisation. However, significant increases after immunisation were noted in $\alpha 4 \beta 7^{\text {hi }}$ lymphocyte populations coexpressing CD69, and trends were observed for CD4 and CD45RO cells. This study therefore shows for the first time that mucosal immunisation with rUrease and LT in humans is able to stimulate a cellular immune response comprising $\mathrm{T}$ helper cells, activated lymphocytes, and memory cells expressing a mucosal homing receptor.

The only other human study of vaccination for H pylori with urease and LT used a vaccination schedule of four weekly doses. ${ }^{15}$ This was a relatively compressed schedule, compared with human vaccination schedules against other infectious agents. In an effort to maximise the immune response, we expanded both the immunisation schedule and the number of doses in this study, by administering four vaccinations over eight weeks to all subjects, and a fifth vaccination at nine weeks to a subgroup. Significant $\alpha 4 \beta 7^{\text {hi }} \quad \mathrm{CD} 4^{+}$and $\alpha 4 \beta 7^{\text {hi }} C D 45 \mathrm{RO}^{\text {hi }}$ lymphocyte responses occurred only at day 73 , after the fifth immunisation. The $\alpha 4 \beta 7^{\text {hi }} \mathrm{CD} 69^{+}$lymphocyte response reached significance by day 64 , after four doses of the vaccine, but rose further by day 73 , after the fifth dose. Future studies should further evaluate the impact of immunisation schedules on immune response to oral immunisation with LT as an adjuvant. In mice, immunisation with attenuated Salmonella typhimurium expressing low level of $H$ pylori urease provided good protection after a single immunisation. ${ }^{26}$ Studies in humans with similar constructs should be performed to determine whether the use of live vectors can also shorten the immunisation schedule in humans.

This study confirms the safety of soluble urease in humans and provides initial evidence of its safety when delivered in enteric release capsules. Furthermore, our results suggest that enterically delivered urease in the form of acid resistant capsules may be more immunogenic than soluble urease in inducing lymphocyte responses. Urease capsules administered with $2.5 \mu \mathrm{g}$ LT elicited significant $\mathrm{CD} 4^{+}, \mathrm{CD} 45 \mathrm{RO}^{\text {hi }}$ and $\mathrm{CD} 69^{+}$ cell responses whereas soluble urease administered with 2.5 $\mu \mathrm{g}$ LT did not. The inferior immunogenicity of soluble urease may be related to acid and peptic degradation and denaturation of the antigen in the stomach. However, the numbers of volunteers in this subgroup were small and the results should be viewed with caution. Larger scale studies are required to more fully compare the immunogenicity of soluble and enterically coated urease.

In conclusion, this study suggests that oral immunisation with urease and LT at a dose of $2.5 \mu \mathrm{g}$ is safe and immunogenic in humans, and is able to elicit humoral as well as cellular mucosal immune responses comprising activated lymphocytes able to home to the gastric mucosa. Enterically coated urease is safe and may be more immunogenic than soluble urease.

\section{ACKNOWLEDGEMENTS}

This study was supported in part by grants from OraVax, Inc Cambridge, MA, and by NIH Grant DK53706 (P.M.) and MOlRR01032 (Beth Israel Deaconess Medical Center General Clinical Research Center, BIDMC-GCRC). The authors thank the nurses and staff of BIDMC-GCRC for their expert assistance and M. Mach for her technical assistance and D Pantoflickova, MD, for her assistance in the statistical analysis. The authors are grateful to the Naval Medical Research Institute, Bethesda, MD, for access to LT used in this study, and to Dr K Eckels, Walter Reed Army Institute of Research, Forest Glen, MD, for the production of recombinant $H$ pylori urease. At OraVax, a number of collaborators contributed to this clinical trial, including W D Thomas, and C Kochi.

\section{Authors' affiliations}

S Baneriee, A Medina-Fatimi, D Tendler, M Michetti, C P Kelly, P Michetti, Beth Israel Deaconess Medical Center and Harvard Medical School, Boston, MA, USA

R Nichols, J Simon, T P Monath, OraVax-Peptide Therapeutics,

Cambridge, MA, USA

\section{REFERENCES}

1 Marshall BJ, Warren JR. Unidentified curved bacilli in the stomach of patients with gastritis and peptic ulceration. Lancet 1984;i:1311-15

2 Forman D, Newell DG, Fullerton F, et al. Association between infection with Helicobacter pylori and risk of gastric cancer: evidence from a prospective investigation. BMU 1991;302:1302-5.

3 Wotherspoon AC, Ortiz-Hidalgo C, Falzon MR, et al. Helicobacter pylori-associated gastritis and primary B-cell gastric lymphoma. Lancet 1991;338:1175-6.

4 Ling TK, Cheng AF, Sung JJ, et al. An increase in Helicobacter pylori strains resistant to metronidazole: a five-year study. Helicobacter 1996; 1:57-61.

5 Fock KM. Peptic ulcer disease in the 1990s: an Asian perspective. $J$ Gastroenterol Hepatol 1997; 12:S23-8.

6 Ramirez-Ramos A, Gilman RH, Leon-Barua R, et al. Rapid recurrence of Helicobacter pylori infection in Peruvian patients after successful eradication. Clin Infect Dis 1997;25:1027-31.

7 Stratton KR, Durch JS, Lawrence RS. Vaccines for the 21 st century: a tool for decision making. Washington, DC: National Academy Press ( in press). Prepublication copy can be viewed on the internet at: http://bob.nap.edu/readingroom/books/vacc2 1 .

8 Chen $M$, Lee A, Hazell S, et al. Immunization against gastric infection with Helicobacter species: first step in the prophylaxis of gastric cancer? Zentrabl Bakteriol 1993;280: 155-65

9 Czinn SJ, Cai A, Nedrud JG. Protection of germ free mice from infection by Helicobacter felis after active oral or passive $\lg \mathrm{A}$ immunization. Vaccine 1993; 139:637-42.

10 Doidge C, Gust I, Lee A, et al. Therapeutic immunization against Helicobacter infection. Lancet 1994;343:913-14.

11 Michetti P, Corthésy-Theulaz I, Davin C, et al. Immunization of BALB/C mice against Helicobacter felis infection with $\mathrm{H}$. pylori urease. Gastroenterology 1994; 107:1002-11

12 Corthésy-Theulaz I, Porta N, Glauser M, et al. Oral immunization with Helicobacter pylori urease B subunit as a treatment against Helicobacter infection in mice. Gastroenterology 1995;109:115-21.

13 Cuenca R, Blancha TG, Czinn SJ, et al. Therapeutic immunization against Helicobacter mustelae in naturally infected ferrets. Gastroenterology 1996;110:1770-5.

14 Kreiss C, Buclin T, Cosma M, et al. Safety of oral immunization with recombinant urease in patients with Helicobacter pylori infection. Lancet 1996;347:1630-1.

15 Michetti P, Kreiss C, Kotloff KL, et al. Oral immunization with urease and Escherichia coli heat-labile enterotoxin is safe and immunogenic in Helicobacter pylori-infected adults. Gastroenterology 1999;1 16:804-12.

16 Williams MB, Butcher EC. Homing of naive and memory T lymphocyte subsets to Peyer's patches, lymph nodes, and spleen. J Immunol 1997; 159:1746-52.

17 Michetti M, Kelly CP, Kraehenbuhl JP, et al. Gastric mucosal alpha(4)beta(7)-integrin-positive CD4 T lymphocytes and immune protection against helicobacter infection in mice. Gastroenterology 2000;1 19:109-18. 
18 Clements JD, Finkelstein RA. Isolation and characterization of homogeneous heat-labile enterotoxins with high specific activity from Escherichia coli cultures. Infect Immun 1979;24:760-9.

19 Czerkinsky C, Svennerholm AM, Quiding M, et al. Antibody-producing cells in peripheral blood and salivary glands after oral cholera vaccination of humans. Infect Immun 1991;59:996-1001.

20 Douce G, Turcotte C, Cropley I, et al. Mutants of Escherichia coli heat-labile toxin lacking ADP-ribosyltransferase activity act as nontoxic, mucosal adjuvants. Proc Natl Acad Sci USA 1995:92:1644-8.

21 Kleanthous H, Myers GA, Georgakopoulos KM, et al. Rectal and intranasal immunization with recombinant urease induce distinct local and serum immune responses in mice and protect against Helicobacte pylori infection. Infect Immun 1998:66:2879-86.

22 Quiding $\mathbf{M}$, Nordström I, Kilander A, et al. Intestinal immune responses in humans. Oral cholera vaccination induces strong intestinal antibody responses and interferon-gamma production and evokes local immunological memory. J Clin Invest 1991;88:143-8.

23 Czerkinsky C, Svennerholm AM, Holmgren J. Induction and assessment of immunity at enteromucosal surfaces in humans: implications for vaccine development. Clin Infec Dis 1993;16 (suppl 2):S106-16.

24 Czerkinsky C, Svennerholm A-M, Quiding M, et al. Antibody-producing cells in peripheral blood and salivary glands after oral cholera vaccination of humans. Infect Immun 1991;59:996-1001.

25 Kantele A, Westerholm M, Kantele JM, et al. Homing potentials of circulating antibody-secreting cells after administration of oral or parenteral protein or polysaccharide vaccine in humans. Vaccine 1999; 17:229-36.

26 Corthésy-Theulaz IE, Hopkins S, Bachmann D et al Mice are protected from Helicobacter pylori infection by nasal immunization with attenuated Salmonella typhimurium phoPc expressing urease $A$ and B subunits. Infect Immun 1998;66:581-6

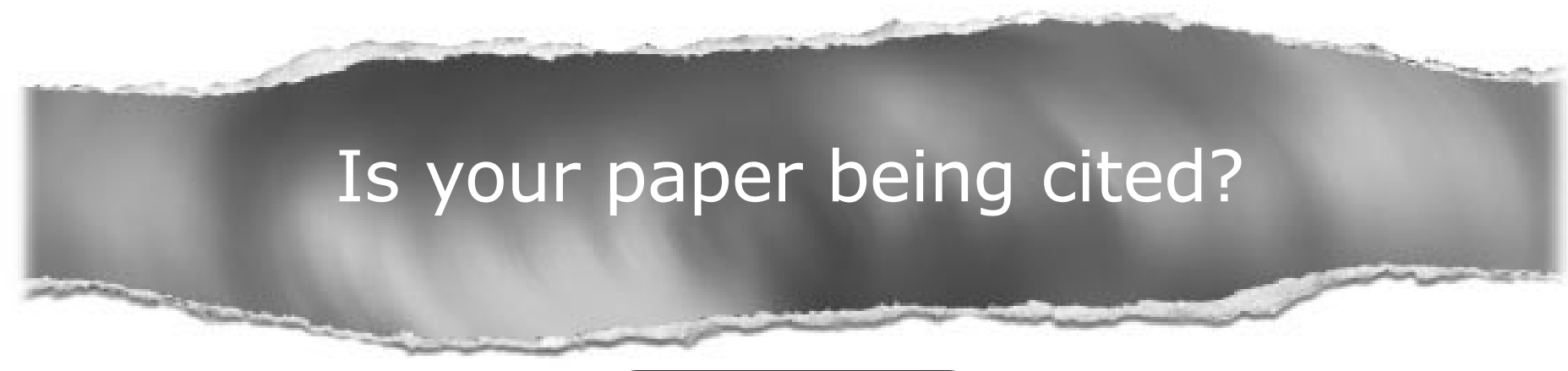

\section{CiteTrack service}

CiteTrack will alert you by email whenever new content in Gut or a participating journal is published that matches criteria you want to track

Topics: Tell CiteTrack which words or subjects to watch for in new content Authors: Be alerted whenever key authors you are following publish a new paper Articles: Know whenever a paper of interest to you is referenced by another paper

\section{www.gutjnl.com}

